\title{
IL-31 and IL-8 in Cutaneous T-Cell Lymphoma: Looking for Their Role in Itch
}

\author{
Maria Abreu, ${ }^{1}$ Marta Miranda, ${ }^{2}$ Mafalda Castro $\mathbb{C}^{3},{ }^{3}$ Iolanda Fernandes $\mathbb{C}$, ${ }^{1,4,5,6}$ \\ Renata Cabral $\mathbb{D}^{1},{ }^{1,3,5,6}$ Ana Helena Santos $\mathbb{D}^{1,3,6}$ Sónia Fonseca $\mathbb{D}^{1,3,6}$ João Rodrigues $\mathbb{D}^{1,3,6}$ \\ Magdalena Leander $\mathbb{D}^{\mathbb{D}},{ }^{1,3,6}$ Catarina Lau $\mathbb{D},{ }^{1,3,6}$ Inês Freitas $\mathbb{D}^{1,},{ }^{1,6,7}$ Susana Coimbra $\mathbb{D}^{8,9}$ \\ Alice Santos-Silva $\mathbb{D}^{2,9}$ and Margarida Lima $\mathbb{D}^{1,3,5,6}$ \\ ${ }^{1}$ Centro Hospitalar Universitário do Porto (CHUP), Porto, Portugal \\ ${ }^{2}$ Faculdade de Farmácia, Universidade do Porto (FFUP), Porto, Portugal \\ ${ }^{3}$ Serviço de Hematologia Clínica, Centro Hospitalar Universitário do Porto (CHUP), Porto, Portugal \\ ${ }^{4}$ Serviço de Dermatologia, Centro Hospitalar Universitário do Porto (CHUP), Porto, Portugal \\ ${ }^{5}$ Consulta Multidisciplinar de Linfomas Cutâneos e Mastocitoses (CMLC), Centro Hospitalar Universitário do Porto (CHUP), \\ Porto, Portugal \\ ${ }^{6}$ Unidade Multidisciplinar de Investigação Biomédica, Instituto de Ciências Biomédicas Abel Salazar, \\ Universidade do Porto (UMIB/ICBAS/UP), Porto, Portugal \\ ${ }^{7}$ Serviço de Hematologia Laboratorial, Centro Hospitalar Universitário do Porto (CHUP), Porto, Portugal \\ ${ }^{8}$ Cooperativa de Ensino Superior Politécnico e Universitário (CESPU), \\ Instituto de Investigação e Formação Avançada em Ciências e Tecnologias da Saúde (IINFACTS), Gandra, Paredes, Portugal \\ ${ }^{9}$ Unidade de Ciências Biomoleculares Aplicadas (UCIBIO), Rede de Química e Tecnologia (REQUIMTE), Porto, Portugal
}

Correspondence should be addressed to Margarida Lima; margaridamariacarvalholima@gmail.com

Received 11 January 2021; Revised 21 June 2021; Accepted 13 July 2021; Published 21 July 2021

Academic Editor: Estella M. Matutes

Copyright (C) 2021 Maria Abreu et al. This is an open access article distributed under the Creative Commons Attribution License, which permits unrestricted use, distribution, and reproduction in any medium, provided the original work is properly cited.

The itch associated with cutaneous T-cell lymphoma (CTCL), including Mycosis Fungoides (MF) and Sézary syndrome (SS), is often severe and poorly responsive to treatment with antihistamines. Recent studies have highlighted the possible role of interleukins in nonhistaminergic itch. We investigated the role of IL-31 and IL- 8 in CTCL, concerning disease severity and associated itch. Serum samples of 27 patients with CTCL (17 MF and 10 SS) and 29 controls (blood donors) were analyzed for interleukin- (IL-) 31 and IL-8; correlations with disease and itch severity were evaluated. IL-31 serum levels were higher in CTCL patients than in controls and higher in SS than in MF. Also, serum IL-31 levels were higher in patients with advanced disease compared to those with early disease, and they correlated positively with lactate dehydrogenase and beta 2-microglobulin levels, as well as with the Sézary cell count. Itch affected 67\% of CTCL patients (MF: 47\%; SS: 100\%). Serum IL-31 levels were higher in itching patients than in controls and in patients without itching. There was no association between serum IL-8 and disease severity, nor with itching. Serum IL-8 levels correlated positively with peripheral blood leukocyte and neutrophil counts in CTCL patients. Our study suggests a role for IL-31 in CTCL-associated itch, especially in advanced disease and SS, offering a rational target for new therapeutic approaches. Increased serum IL-8 observed in some patients may be related to concomitant infections, and its role in exacerbating itch by recruiting neutrophils and promoting the release of neutrophil proteases deserves further investigation. 


\section{Introduction}

Cutaneous T-cell lymphomas (CTCLs), classically represented by Mycosis Fungoides (MF) and Sézary Syndrome (SS), account for $70 \%$ of cutaneous lymphomas and $10 \%$ of extranodal non-Hodgkin's lymphomas [1]. These chronic pathologies reduce the patient's quality of life [2], and the prognosis depends on the CTCL type and stage [3].

Pruritus, or itch, a frequent feature in CTCL, is particularly severe in patients with SS $[4,5]$, being often recalcitrant and refractory to treatment $[6,7]$, thus motivating the study of the pathways involved [8].

Histamine has been shown to cause itching [9], and antihistamines are the most prescribed medications for itch [10]. Nevertheless, CTCL-associated itching is usually refractory to antihistamines, suggesting alternative pathways to its genesis.

Molecules suspected to be involved in nonhistaminergic itch include neurotransmitters [11-16], lipid mediators [17-20], and proteases, via proteinase-activated receptors (PARs) [21], as well as cytokines and chemokines [22].

Among the cytokines potentially implicated is interleukin- (IL-) 31, produced mainly by T helper 2 cells (Th2) [23]. IL-31 signals through a heterodimeric receptor [24] and stimulates the JAK-STAT, RAS/ERK, and PI3K/AKT pathways [25]. It does not induce itch immediately after skin challenge [26] but has receptors in the dorsal root ganglia [27] and is a likely mediator in nonhistaminergic itch $[28,29]$.

Previous studies have suggested the involvement of IL-31 in itching diseases including atopic dermatitis (AD) [30-39], other pathological conditions [40-45], drug-induced itch [46], and neoplastic diseases, such as CTCL [47-53].

Some studies have reported increased IL-31 serum levels (sIL-31) in itching diseases, and most of them have provided evidence for a positive correlation between sIL-31 and itch severity in $\operatorname{AD}[31,32,34,36]$ and CTCL $[47,49,50]$, with some contradictory results $[51,52]$. In addition, the expression of IL-31 mRNA, IL-31, and its receptors has been shown to be increased in $\mathrm{AD}[32,33,48]$ and CTCL $[49,53]$ skin lesions and to correlate with itch severity and disease stage. IL-31 receptors have also been described in the nerve fibers of the $\mathrm{AD}$ dermis and in normal dorsal root ganglia, which mediate the sensation of itch [38]. Finally, specific IL31 gene polymorphisms have been associated with itch and $\mathrm{AD}$ severity [37, 39].

Bacterial infections, namely, skin infections, occur frequently in patients with CTCL, and bacteremia and pneumonia are frequent causes of death [54]; cutaneous colonization with staphylococci is common, especially in SS, worsening both erythroderma and itching $[55,56]$.

Microorganisms can induce and/or exacerbate the inflammatory responses due to secretion of proinflammatory cytokines, namely, IL-8 [57], involved in neutrophil chemotaxis $[58,59]$. Increased IL- 8 serum levels (sIL-8) have been described in $\mathrm{AD}$ [60] and psoriasis [61, 62], being higher in more severe conditions and improving with treatment. Increased IL-8 mRNA was also found in peripheral blood $(\mathrm{PB})$ mononuclear cells of $\mathrm{AD}$ patients [63].
However, IL- 8 does not induce itch upon cutaneous injection, and a direct role of IL- 8 in itch is unlikely $[64,65]$. Another study showed that sIL-8 did not correlate with pruritus in primary myelofibrosis [66].

Considering the prevalence and severity of itch in CTCL and its resistance to treatment, we decided to investigate the role of IL-31 and IL-8 in the pathophysiology of itch in CTCL.

\section{Materials and Methods}

2.1. Study Population. The study group included CTCL patients and healthy controls (blood donors). Patients with evidence of active infections or other concomitant neoplasms were excluded.

2.2. Clinical Data. Clinical data were obtained from hospital records and comprise lymphoma classification and staging, type and extension of the cutaneous lesions, the presence and intensity of itch, treatments, concomitant diseases, and past clinical history.

The diagnosis and classification of CTCL followed the recommendations of the European Organization for $\mathrm{Re}$ search and Treatment of Cancer (EORTC)/World Health Organization (WHO) [67-69].

Lymphoma TNMB (tumor-node-metastasis-blood) staging was established using the ISCL/EORTC proposal [70].

Erythroderma was evaluated using a scale with 5 levels $(0=$ normal; 1 = barely detectable erythema and scaling; 2 = readily detectable erythema, edema, and scaling; $3=$ marked erythema and skin exfoliation; and $4=$ fissuring, maximal erythema, induration, and tumors) and quantifying the percentage of cutaneous area afflicted [71].

Itch severity was assessed through a visual analogue scale (VAS), ranging from the absence of itch ( 0 points) to the highest itch intensity (10 points). Arbitrarily, itch scaled from 1 to 5 points was considered mild/moderate and itch ranging from 6 to 10 points was considered intense/severe.

2.3. Laboratory Studies. Blood samples were collected into anticoagulant-free tubes for quantifying serum cytokines and into tubes containing ethylenediaminetetraacetic acid, for cell counts and lymphocyte immunophenotyping.

Serum cytokine levels were quantified through the LEGEND MAX ${ }^{\text {тм }}$ Human IL-8 and IL-31 Enzyme-Linked Immunosorbent Assays (Biolegend, U.S.A.).

Blood cell counts were obtained through an automatic hematological counter (LH780, Beckman Coulter, U.S.A.). Confirmation of differential leukocyte count and the search for SC by morphology were performed through optic microscopy in PB smears (Leishman's stain).

Biochemical analysis included glucose, liver, and kidney tests, beta 2 microglobulin (B2MG), and lactate dehydrogenase (LDH), among others.

Lymphocyte immunophenotyping was made by flow cytometry, using 4- or 8-color staining with fluorochromeconjugated monoclonal antibodies specific, at least, for CD2, 
CD3, TCR, CD4, CD5, CD7, CD8, CD26, and CD28 and completed with the study of TCR variable region beta chain repertoire (Immunotech, Beckman Coulter), as previously described [72]. Samples were read in a FACSCanto II flow cytometer (Becton Dickinson, U.S.A.) and analyzed though the Infinicyt program (Cytognos, Spain).

TCRG gene rearrangement studies were performed as previously described [73], using the TCRG Gene Clonality Assay (InVivo Scribe Technologies, U.S.A.) and following the Biomed II protocol [74]. Data were analyzed using the Peak Scanner Software v1.0 (Thermo Fisher Scientific, U.S.A.).

2.4. Statistical Analysis. Results were presented as relative and absolute frequencies for qualitative variables and as median, range, and mean \pm standard deviation for continuous quantitative variables. Data distribution was evaluated by Kolmogorov-Smirnov analysis. For comparison between groups, we used, for continuous variables, the Mann-Whitney $U$ test; for categorical variables, the chi-squared test was employed. Strength of correlations between variables was determined through Kendall's tau-B correlation coefficient. $p$ values $<0.05$ were considered statistically significant. Data analysis was performed with the Statistical Package for the Social Sciences $\left(\mathrm{SPSS}^{\circledR}\right)$, v23.

\section{Results}

Twenty-seven CTCL patients (median age: 66 years; $51.9 \%$ males) and 29 controls (median age: 58 years; $48.3 \%$ males) were included. Among patients, all having active disease, 17 (63\%) were diagnosed with MF and 10 (37\%) had SS (Table 1).

All patients had skin lesions of any sort, most often patches $(63.0 \%)$, plaques (29.6\%), and erythroderma (9 patients, all with SS). The affected skin surface area was $<10 \%$ in 8 patients $(29.6 \%)$ and $\geq 80 \%$ in 11 patients $(40.7 \%)$, 9 of whom having SS. At the time of study, only 2 patients had palpable lymph nodes. In addition, 11 patients $(40.7 \%)$ had SC in the PB; the percentage of SC among total lymphocytes was $>5 \%$ in 10 cases $(37.0 \%)$, and the SC count exceeded 1000 cells/ $\mu \mathrm{l}$ in 5 cases $(18.5 \%)$, given blood involvement to be classified as B0b in 1 case, B1b in 5 cases, and $\mathrm{B} 2 \mathrm{~b}$ in another 5 cases. Using the TMNB staging, 9 patients were classified as stage Ia, 8 as stage Ib, 1 as stage IIb, 4 as stage IIIb, and 5 as stage IVa.

Eighteen patients $(66.7 \%)$ complained of itch at the time of the study, this symptom being observed in all SS patients, and only in $47.8 \%$ of patients with MF. The median itch VAS score for all patients was of " 1 ," being of " 1 " for patients with early disease and of " 10 " for patients with advance disease $(p<0.001)$. The highest itch scores were found in SS patients, who had a median VAS score of "9," as compared to “ 0 " in MF $(p=0.001)$. Itch was classified as mild/moderate in 7 patients $(25.9 \%)$ and as intense/severe in 11 patients $(40.7 \%)$, with a higher proportion of SS patients referring intense/severe itch (80\%), as compared to MF (17.6\%).
Eighteen patients $(66.7 \%)$ were under therapy directed at the disease: topical corticosteroids $(10 / 27,37.0 \%)$, methotrexate $(4 / 27,14.8 \%)$, oral bexarotene $(2 / 27,7.4 \%)$, oral corticosteroids $(2 / 27,7.4 \%)$, and extracorporeal photopheresis $(1 / 27,3.7 \%)$. As for symptomatic treatment and besides corticosteroids, 11 patients $(40.7 \%)$ were taking antihistamines, 1 patient was medicated with mirtazapine, and another with aprepitant.

Eleven patients (40.7\%) had concomitant pathologies, of whom 2 patients had psoriasis and 2 had alcoholic liver disease. In addition, 2 patients had a history of other neoplasm (carcinoma of the thyroid gland and gastric adenocarcinoma), in remission at the time of study.

The hematologic study (Table 2) showed 3 patients with leukocytosis and one with neutrophilia; 9 patients had lymphopenia, and 3 had lymphocytosis. Anemia was found in 7 patients, but only one had $\mathrm{Hg}^{<} 10 \mathrm{~g} / \mathrm{dL}$, who also presented thrombocytopenia.

Eleven patients (40.7\%) (10 SS, $1 \mathrm{MF}$ ) had CD4+ lymphoma cells in the $\mathrm{PB}$ (Table 2). In these cases, the phenotypically abnormal CD4+ T cells represented a median value of $82.9 \%$ of the CD $4+\mathrm{T}$ cells, $69.3 \%$ of T cells, $48.2 \%$ of lymphocytes, and $11.1 \%$ of WBC, being $>5 \%$ of PB lymphocytes in 10 patients (27.0\%), classified as B1 or B2. The median count of CD4+ lymphoma cells was of $604 \times 10^{6} / \mathrm{L}$, being $\geq 1000 / \mu \mathrm{l}$ in 5 cases (B2) (18.5\%), corresponding to patients with SS.

The malignant $\mathrm{T}$ cells were typically $\mathrm{CD} 3+, \mathrm{TCR}-$ alpha/beta+, CD4+, and CD5+, failed to express CD26, and frequently had abnormally low levels of CD3 and/or CD4, as well as low or absent CD7 expression (data not shown). The TCR-Vbeta family expressed by circulating SC was identified in $8 / 11$ cases $(72.7 \%)$, corresponding to TCR-Vbeta17.1 $(n=3), \quad$ TCR-Vbeta5.1 $\quad(n=2), \quad$ and TCR-Vbeta3.1, TCR-Vbeta20.1, or TCR-Vbeta22.1 (1 case each).

Fifty percent of patients with CTCL had increased LDH $(25.0 \%$ of MF cases and $80.0 \%$ of SS cases), and $34.8 \%$ had increased B2MG (21.4\% of MF and $55.6 \%$ of SS cases) (Table 2). LDH and B2MG were significantly higher in SS, as compared to MF ( $p=0.002$ and $p=0.027$, respectively). Abnormal liver tests were found in 2 patients with alcoholic liver disease; one patient had mild renal insufficiency.

3.1. Interleukin-31. Interleukin-31 levels in CTCL patients were significantly higher than those in controls $(p=0.012)$ (Table 3 and Figure 1(a)). Also, SS patients had significantly higher sIL-31 when compared to patients with MF $(P=0.004)$ and to controls $(p<0.001)$. In contrast, sIL-31 did not differ significantly between MF patients and controls $(p>0.05)$ (Table 3 and Figure 1(a)).

Concerning CTCL stages, patients with advanced disease had significantly higher sIL-31 as compared to patients with early disease $(p=0.026)$ and to controls $(p<0.001)$ (Table 3). No significant differences were observed between patients with early disease and controls $(p>0.05)$. Moreover, sIL-31 correlated significantly with LDH $(p=0.001)$ and B2MG $(p=0.009)$ (Figures 2(a) and 2(b)). 
TABLE 1: Sociodemographic and clinical characteristics of the CTCL study population.

\begin{tabular}{|c|c|}
\hline Age (years) & $66(36-90)$ \\
\hline Gender (male/female) & $14(51.9 \%) / 13(48.1 \%)$ \\
\hline \multicolumn{2}{|l|}{ CTCL classification } \\
\hline Mycosis Fungoides & $17(63.0 \%)$ \\
\hline Sézary syndrome & $10(37.0 \%)$ \\
\hline \multicolumn{2}{|l|}{ Time of evaluation } \\
\hline At the diagnosis & $5(18.5 \%)$ \\
\hline During disease follow-up & $22(81.5 \%)$ \\
\hline \multicolumn{2}{|l|}{ Skin lesions, at the time of the study } \\
\hline Patches & $17(63.0 \%)$ \\
\hline Plaques & $8(29.6 \%)$ \\
\hline Papules & $2(7.4 \%)$ \\
\hline Nodules & $1(3.7 \%)$ \\
\hline Tumors & $1(3.7 \%)$ \\
\hline Erythroderma $\ddagger$ & $9(33.3 \%)$ \\
\hline \multicolumn{2}{|c|}{ Body surface area affected, at the time of the study } \\
\hline$<10$ & $8(29.6 \%)$ \\
\hline$[10-80 \%]$ & $8(29.6 \%)$ \\
\hline$\geq 80 \%$ & $11(40.7 \%)$ \\
\hline \multicolumn{2}{|l|}{ Disease stage, at the time of the study } \\
\hline Stages I and II & $18(66.7 \%)$ \\
\hline Stages III and IV & $9(33.3 \%)$ \\
\hline \multicolumn{2}{|l|}{ Pruritus, at the time of the study } \\
\hline Yes (score 1 to 10$)$ & $18(66.7 \%)$ \\
\hline Mild/moderate (score 1 to 5 ) & $7(25.9 \%)$ \\
\hline Intense/severe (score 6 to 10 ) & $11(40.7 \%)$ \\
\hline VAS score, all patients & $1(0-10) ; 4 \pm 4$ \\
\hline VAS score, early disease/advanced disease & $1(0-10) ; 2 \pm 3 / 10(5-10) ; 9 \pm 2$ \\
\hline VAS score, MF patients/SS patients & $0(0-10) ; 2 \pm 3 / 9(1-10) ; 8 \pm 3$ \\
\hline \multicolumn{2}{|l|}{ Treatment, at the time of the study } \\
\hline Directed to the disease & $18(66.7 \%)$ \\
\hline Directed to itch & $19(70.4 \%)$ \\
\hline
\end{tabular}

Results are presented as median (range), mean \pm standard deviation, and as absolute and relative frequencies. CTCL, cutaneous T-cell lymphoma; MF, Mycosis Fungoides; SS, Sézary syndrome; VAS, visual analogue scale. $¥$ One SS patient bore no erythroderma at the time of the evaluation.

Considering the hematological and immunophenotypic variables, CTCL patients with percentages of SC $>5 \%$ of total lymphocytes had significantly higher sIL-31 levels compared to those having $\leq 5 \%(p=0.008)$ (Table 3$)$.

A positive correlation between SIL-31 and the number of abnormal CD4+ T cells in PB was observed, when considering all CTCL patients $(p=0.008)$. However, when analyzing only SS patients, the significance was lost.

sIL-31 was significantly higher in CTCL patients complaining of itch, as compared to those without itch $(p=0.021)$ and to controls $(p=0.002) \quad$ (Table 3) (Figure 1(a)). Similarly, sIL-31 was significantly higher in CTCL patients reporting intense/severe itch when compared to patients reporting mild/moderate itch $(p=0.037)$ (Table 3). Correspondingly, there was a significant higher sIL-31 in CTCL patients reporting intense/severe itch, but not in CTCL patients mentioning mild/moderate itch, as compared with controls ( $p<0.001$ and $p>0.05$, respectively) (Table 3 ).

In CTCL patients, sIL-31 correlated significantly with the itch VAS score $(p<0.001)$ (Figure $2(\mathrm{c}))$. When analyzing only MF patients, a relationship between sIL-31 and itch was also noted, as MF patients with intense/severe itch had significantly higher sIL-31, as compared to those with mild/ moderate itch $(p=0.036)$.
3.2. Interleukin-8. Interleukin-8 levels did not differ significantly neither between patients and controls nor between the groups of CTCL patients mentioned above, when compared to each other and when compared to controls ( $p>0.05$ in all situations) (Table 3 and Figure 1(b)).

Considering the hematological and immunophenotypic variables, there was a positive correlation between sIL-8 and WBC $(p=0.030)$ and neutrophil $(p=0.021)$ counts; however, after excluding one IL-8 outlier, the statistical significance was lost (Figures 3(a) and 3(b)).

No significant differences were observed in sIL- 8 between CTCL patients with or without itch $(p>0.05)$, nor between these groups and controls $(p>0.05)$. However, there was a tendency to higher sIL-8 in patients classifying itch as intense/severe, compared to mild/moderate $(p=0.056)$.

\section{Discussion}

IL-31 has been associated to pruritic diseases [30-53], being consensual that it has a role in nonhistaminergic itch [22]. Our study suggests a relationship between IL-31 and CTCL disease severity and associated itch, supporting and complementing other studies [47, 49]. 
TABLE 2: Laboratorial features of the CTCL study population, at the time of the study.

\begin{tabular}{|c|c|}
\hline \multicolumn{2}{|l|}{ Blood cell counts and cytomorphology } \\
\hline Leucocytes $(x 109 / \mathrm{L})$ & $7.30(4.50-130.70)$ \\
\hline Neutrophils (x109/L) & $4.28(1.84-15.82)$ \\
\hline Lymphocytes (x109/L) & $2.34(0.20-96.20)$ \\
\hline Monocytes (x109/L) & $0.57(0.08-17.25)$ \\
\hline Hemoglobin $(\mathrm{g} / \mathrm{dL})$ & $13.7(8.6-16.5)$ \\
\hline Platelets $(\times 109 / \mathrm{L})$ & $220(42-357)$ \\
\hline Atypical lymphocytes/SC (\% leucocytes) & $0.0(0.0-66.5)$ \\
\hline \multicolumn{2}{|l|}{ Abnormal blood cell counts } \\
\hline Leukocytosis $\left(>11 \times 10^{9} / \mathrm{L}\right)$ & $3 / 27(11.1 \%)$ \\
\hline Neutrophilia $\left(>7.0 \times 10^{9} / \mathrm{L}\right)$; neutropenia $\left(<1.5 \times 10^{9} / \mathrm{L}\right)$ & $1 / 27(3.7 \%) ; 0 / 27(0.0 \%)$ \\
\hline Lymphocytosis $\left(>3.5 \times 10^{9} / \mathrm{L}\right)$; lymphopenia $\left(<1.5 \times 10^{9} / \mathrm{L}\right)$ & $3 / 27(11.1 \%) ; 9 / 27(33.3 \%)$ \\
\hline Anemia $(\mathrm{hg}<12.0 \mathrm{~g} / \mathrm{dL})$ & $7 / 27(25.9 \%)$ \\
\hline Thrombocytopenia $\left(<100 \times 10^{9} / \mathrm{L}\right)$ & $1 / 27(3.7 \%)$ \\
\hline \multicolumn{2}{|l|}{ Lymphocyte immunophenotyping } \\
\hline CD $4+\mathrm{T}$-cell count $/ \mu \mathrm{L}$ & $930(23-93329)$ \\
\hline $\mathrm{CD} 4 / \mathrm{CD} 8$ ratio & $2.8(0.6-99.0)$ \\
\hline \multicolumn{2}{|l|}{ Phenotypically abnormal CD4+ SC } \\
\hline \% CD4+ T cells & $0.0(0.0-98.0)$ \\
\hline$\%$ leucocytes & $0.0(0.0-70.7)$ \\
\hline Cell counts $/ \mu \mathrm{l}$ & $0(0-92395)$ \\
\hline \multicolumn{2}{|l|}{ Blood involvement } \\
\hline Yes & $11(40.7 \%)$ \\
\hline Stage B0 (SC $<5 \%$ lymphocytes) & $17(62.9 \%) \dagger$ \\
\hline Stage B1 (SC > 5\% lymphocytes, $<1000 \mathrm{CS} / \mu \mathrm{L})$ & $5(18.5 \%)$ \\
\hline Stage $\mathrm{B} 2(\mathrm{SC}>1000 \mathrm{CS} / \mu \mathrm{L})$ & $5(18.5 \%)$ \\
\hline \multicolumn{2}{|l|}{ Biochemistry } \\
\hline B2MG (mg/L) & $2.10(1.20-14.70)$ \\
\hline Increased B2MG (>2.53 mg/L) & $8 / 23(34.8 \%)$ \\
\hline $\mathrm{LDH}(\mathrm{U} / \mathrm{L})$ & $224(128-656)$ \\
\hline Increased LDH (>225 U/L) & $11 / 22(50.0 \%)$ \\
\hline Abnormal liver tests & $2 / 27(67.4 \%)$ \\
\hline Abnormal kidney tests & $1 / 27(3.7 \%)$ \\
\hline
\end{tabular}

Results are presented as median (range) and as absolute and relative frequencies. CTCL, cutaneous T-cell lymphoma; CS, Sézary cells; B2MG, beta 2 microglobulin; LDH, lactate dehydrogenase; MF, Mycosis Fungoides; SS, Sézary syndrome. †One patient had circulating CD4+ SC, although they represent only $2.9 \%$ of CD $4+\mathrm{T}$ cells, $1.8 \%$ of lymphocytes, and $0.4 \%$ of leukocytes.

TABLE 3: IL-31 and IL-8 serum levels in patients with CTCL and healthy controls.

\begin{tabular}{|c|c|c|c|c|c|c|}
\hline & sIL-31 (pg/ml) & P (CTCL vs. C) & $\mathrm{P}(\mathrm{CTCL}) \dagger$ & sIL-8 (pg/ml) & $\mathrm{P}(\mathrm{CTCL} v s . \mathrm{C})$ & $\mathrm{P}(\mathrm{CTCL}) \dagger$ \\
\hline Controls $(n=29)$ & $7.8(0.3-55.3)$ & NA & NA & $9.3(3.4-52.0)$ & NA & NA \\
\hline CTCL $(n=27)$ & $24.2(0.6-253.6)$ & 0.012 & NA & $11.1(3.4-322.5)$ & 0.863 & NA \\
\hline $\operatorname{MF}(n=17)$ & $11.4(0.6-58.6)$ & 0.333 & \multirow{2}{*}{0.004} & $11.1(3.4-31.2)$ & 1.000 & \multirow{2}{*}{0.639} \\
\hline SS $(n=10)$ & $28.3(17.3-253.6)$ & $<0.001$ & & $13.0(4.2-322.5)$ & 0.740 & \\
\hline SC $\leq 5 \%$ lymphocytes $(n=17)$ & $11.4(0.6-253.6)$ & 0.322 & \multirow{2}{*}{0.008} & $10.1(3.4-31.2)$ & 0.802 & \multirow{2}{*}{0.334} \\
\hline SC $>5 \%$ lymphocytes $(n=10)$ & $28.3(17.3-209.1)$ & $<0.001$ & & $18.3(4.2-322.5)$ & 0.495 & \\
\hline $\mathrm{SC}<1000 / \mu \mathrm{l}(n=22)$ & $21.9(0.6-253.6)$ & 0.070 & \multirow{2}{*}{0.138} & $10.7(3.4-31.2)$ & 0.581 & \multirow{2}{*}{0.033} \\
\hline $\mathrm{SC} \geq 1000 / \mu \mathrm{l}(n=5)$ & $28.3(17.3-60.6)$ & 0.003 & & $30.1(6.0-322.5)$ & 0.056 & \\
\hline Stages I + II $(n=18)$ & $12.2(0.6-253.6)$ & 0.212 & \multirow{2}{*}{0.026} & $9.3(3.4-31.2)$ & 0.991 & \multirow{2}{*}{0.596} \\
\hline Stages III + IV $(n=9)$ & $28.3(17.3-209.1)$ & $<0.001$ & & $15.8(4.2-322.5)$ & 0.736 & \\
\hline Without itch (VAS 0) $(n=9)$ & $11.4(0.6-30.1)$ & 0.430 & \multirow{2}{*}{0.021} & $9.3(3.9-31.2)$ & 0.783 & \multirow{2}{*}{0.743} \\
\hline With itch (VAS $1-10)(n=18)$ & $27.7(1.4-253.6)$ & 0.002 & & $11.4(3.4-322.5)$ & 0.726 & \\
\hline Mild/moderate itch (VAS 1-5) $(n=7)$ & $7.8(1.4-253.6)$ & 0.749 & \multirow{2}{*}{0.037} & $8.2(3.4-26.1)$ & 0.253 & \multirow{2}{*}{0.056} \\
\hline Intense/severe itch (VAS 6-10) $(n=11)$ & $28.3(17.3-209.1)$ & $<0.001$ & & $20.8(4.2-322.5)$ & 0.175 & \\
\hline
\end{tabular}

Results are presented as mean \pm standard deviation and as median and (range) values. Values were rounded to one decimal point. C, controls; CTCL, cutaneous T-cell lymphomas; sIL-8, interleukin-8 serum levels; sIL-31, interleukin-31 serum levels, MF, Mycosis Fungoides; NA, not applicable; PB, peripheral blood; SC, Sézary cells; SS, Sézary syndrome; VAS, visual analogue scale. $\dagger p$ values obtained when the mentioned CTCL groups were compared to each other, including outliers: MF $v s$. SS, CTCL with $\leq 5 \%$ SC $v s$. CTCL with $>5 \%$ SC (expressed as $\%$ of PB lymphocytes); CTCL with SC $<1000 / \mu \mathrm{L} v s$. CTCL with SC $\geq 1000 / \mu \mathrm{L}$ in the PB; CTCL stages I + II $v s$. CTCL stages III + IV; CTCL without itch (VAS 0) vs. CTCL with itch (VAS 1-10); CTCL with mild/ moderate itch (VAS 1-5) vs. CTCL with intense/severe itch (VAS 6-10). 


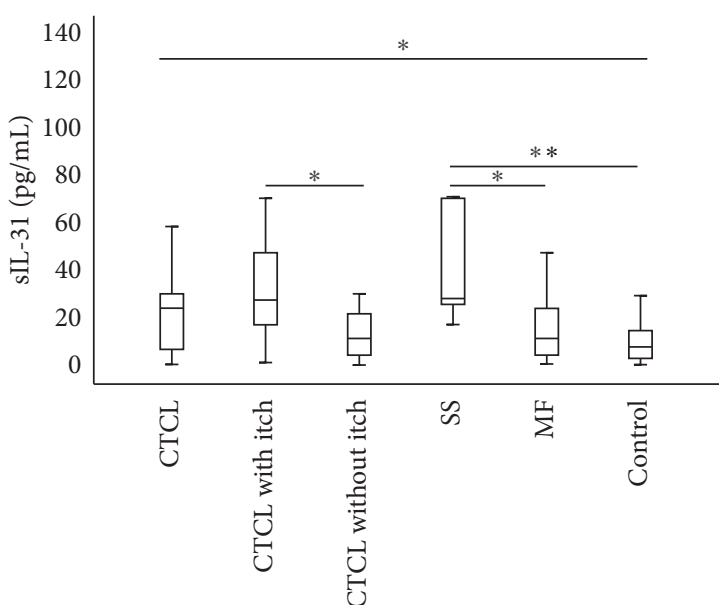

(a)

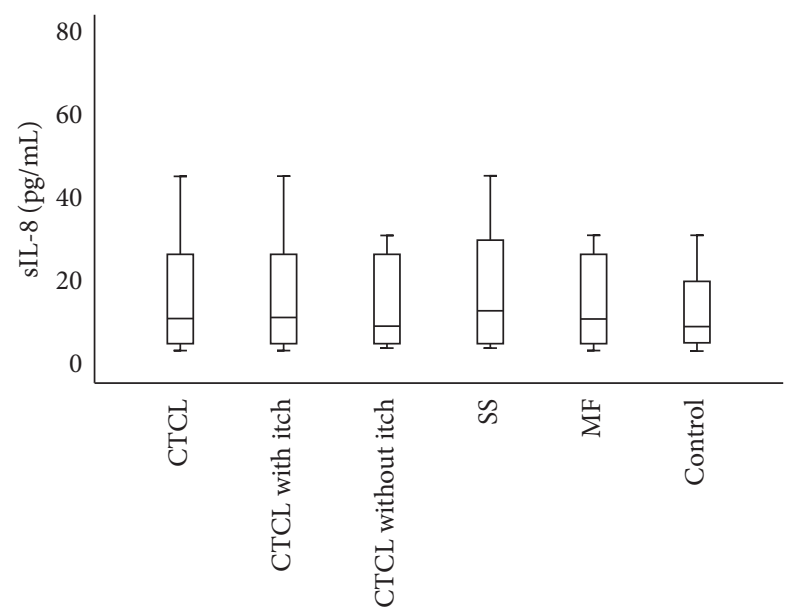

(b)

FIGURE 1: IL-31 (a) and IL-8 (b) serum levels according to diagnosis and to the presence of itch. In this figure, 2 outliers were excluded for sIL-31 (sIL$31>200 \mathrm{pg} / \mathrm{mL}$ ) and 1 outlier was excluded for IL-8 (sIL-8 $>200 \mathrm{pg} / \mathrm{mL}$ ). Statistical analysis was performed using the Mann-Whitney $U$ test. ${ }^{*} p<0.05 ;{ }^{* *} p<0.01$; and ${ }^{* * *} p<0.001$. Statistics for sIL-31 (including/excluding the outliers): CTCL $v s$. controls: $p=0.012 / p=0.032$; MF $v s$. controls: $p=0.333 / p=0.333$; SS vs. controls: $p<0.001 / p=0.001$; MF $v$. SS: $p=0.004 / p=0.024$; CTCL without itch $v$ s. controls: $p=0.430 / p=0.649$; CTCL with itch $v$ s. controls: $p=0.002 / p=0.007$; and CTCL with itch $v$ s. CTCL without itch: $p=0.021 / p=0.048$. Statistics for sIL-8 (including/excluding 1 CTCL outlier, corresponding to a patient with hyperleukocytosis and sIL-8 $>200 \mathrm{pg} / \mathrm{mL}$ ): CTCL $v s$. controls: $p=0.863 / p=0.946$; MF $v$. controls: $p=1.000 / p=1.000$; SS $v s$. controls: $p=0.740 / p=0.893$; MF $v$ s. SS: $p=0.639 / p=0.958$; CTCL without itch vs. controls: $p=0.783 / p=0.914$; CTCL with itch $v s$. controls: $p=0.726 / p=0.973$; and CTCL with itch $v s$. CTCL without itch: $p=0.743 / p=0.916$. CTCL, cutaneous T-cell lymphoma; MF, Mycosis Fungoides; SS, Sézary syndrome; sIL-8, interleukin-8 serum levels; and sIL-31, interleukin-31 serum levels.

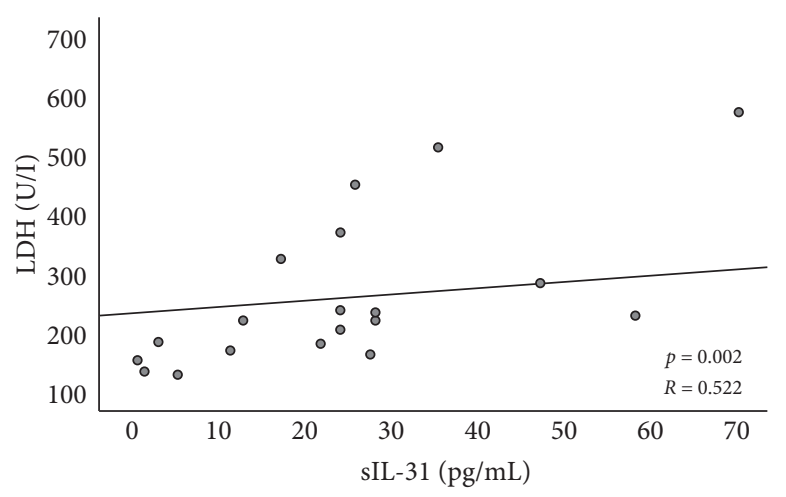

(a)

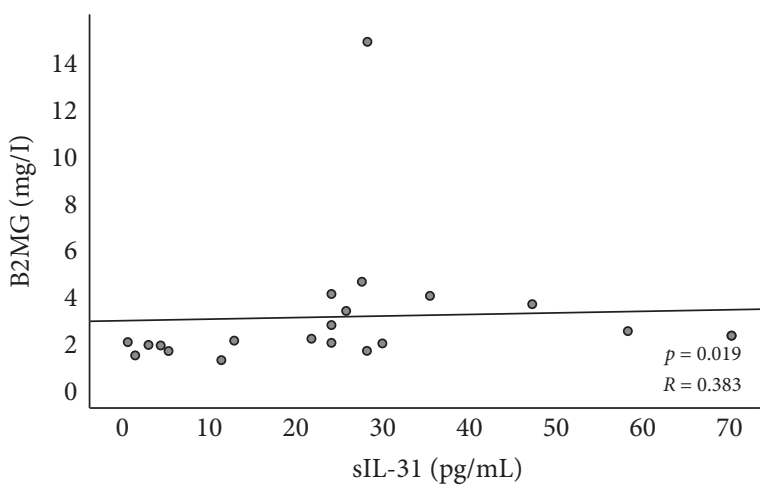

(b)

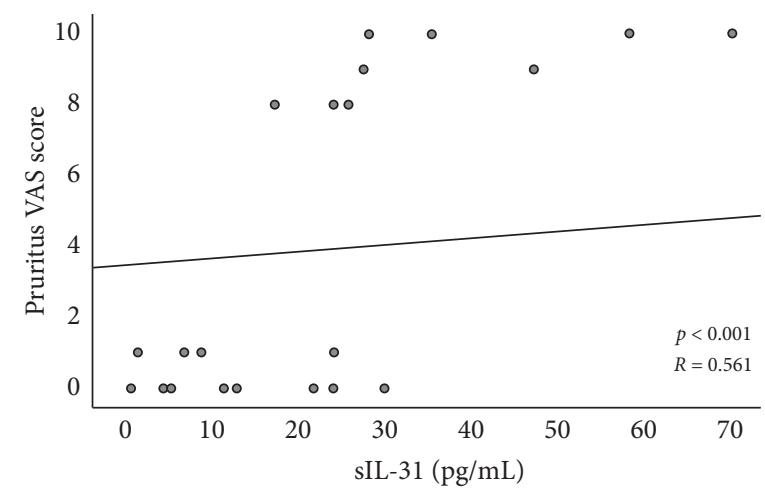

(c)

Figure 2: Correlations between IL-31 serum levels and LDH serum levels (a), B2MG serum levels (b), and itch VAS score (c). In this figure, 2 outliers were excluded for correlations involving sIL-31 (sIL-31>200 pg/mL), and the $p$ and R values presented refer to analysis excluding outliers. Statistical analysis was performed using Kendall's tau-B correlation coefficient. Statistics (including/excluding the outliers): sIL-31 vs. LDH: $p=0.001$; $R=0.545 / p=0.002 ; R=0.522 ;$ sIL-31 vs. B2M: $p=0.009 ; R=0.406 / p=0.019 ; R=0.383$; sIL-31 vs. SC count: $p=0.008 ; R=0.406 / p=0.012$; $R=0.423$; and sIL-31 vs. pruritus VAS score: $p<0.001 ; R=0.530 / p<0.001 ; R=0.561$. B2M, beta 2 microglobulin; CTCL, cutaneous T-cell lymphoma; IL, interleukin; LDH, lactate dehydrogenase; SC, Sézary cells; and sIL-31, interleukin-31 serum levels. 


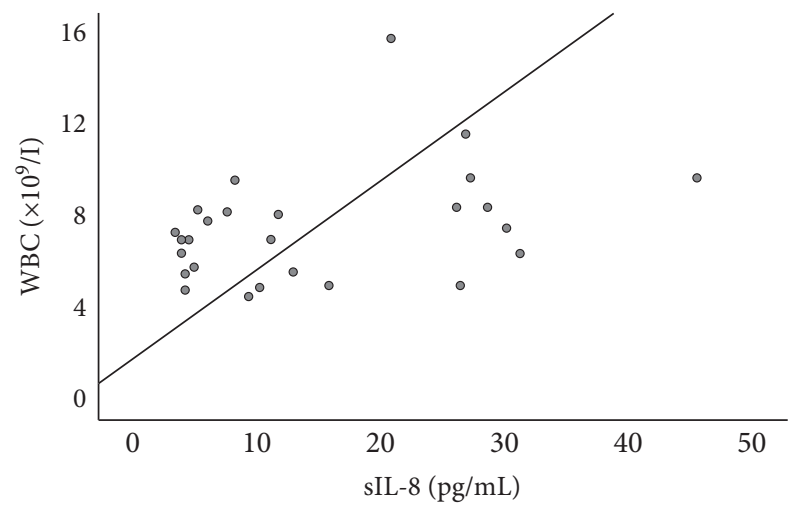

(a)

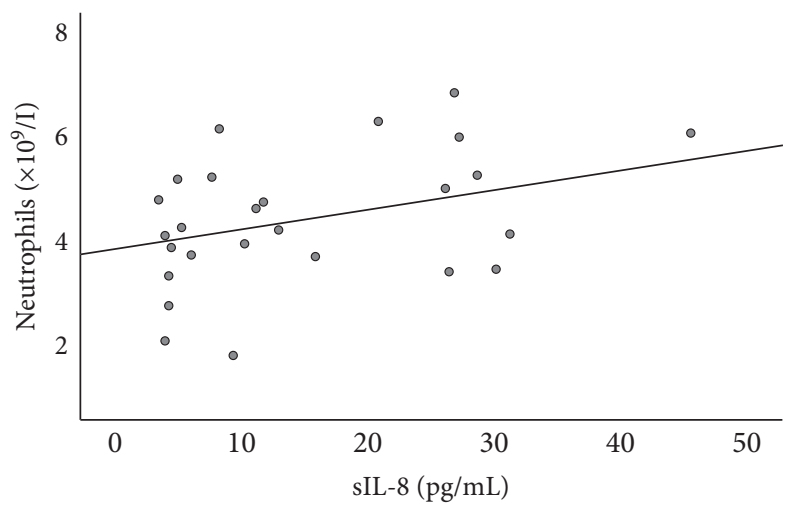

(b)

FIGURE 3: Correlations between IL-8 serum levels and peripheral blood leukocyte (a) and neutrophil (b) counts, in patients with CTCL. In this figure, 1 outlier was excluded for correlations involving sIL-8 (sIL-8 $>200 \mathrm{pg} / \mathrm{mL}$, corresponding to a patient with hyperleukocytosis). Statistical analysis was performed using Kendall's tau-B correlation coefficient. Statistics (including/excluding the outliers): sIL-8 vs. leukocyte count: $p=0.030 ; R=0.300 / p=0.085 ; R=0.243$; sIL-8 vs. neutrophil count: $p=0.021 ; R=0.317 / p=0.061 ; R=0.262$. CTCL, cutaneous T-cell lymphoma; IL, interleukin; sIL-8, interleukin-8 serum levels; and WBC, white blood cell.

With respect to disease severity, we found sIL-31 to be higher in advanced CTCL cases and to correlate significantly with $\mathrm{LDH}$ and B2MG, which reflect tumor burden [75]. In this aspect, our results are similar to those obtained by Ohmatsu et al., who observed a positive association between sIL-31 and disease gravity in CTCL but did not investigate the relationship between sIL-31 and itch [47]. In addition, we noticed a significant positive correlation between sIL-31 and the number of PB lymphoma cells, strengthening the hypothesis that IL-31 is produced by the malignant $\mathrm{T}$ cells $[49,50]$.

Concerning itch, we found sIL-31 to be significantly higher in CTCL patients suffering from itch as compared to those without itch, just as they were significantly higher in patients with intense/severe vs. those with mild/moderate itch; we also observed a positive correlation between the sIL31 and the itch VAS score. Our results are coherent with those obtained by Singer et al. [49], but not with those obtained in other studies [51, 52]. Indeed, Singer et al. observed that sIL-31 was higher in itching as compared to nonitching CTCL patients [49], whereas Malek et al. found that sIL-31 was higher in CTCL patients than in controls, but they did not observe significant differences between itching and nonitching cases, nor a positive correlation between sIL31 and the itch score [51].

Previous studies have shown a Th2-biased immune response in advanced CTCL, whereas in early disease, a Th1 profile predominates $[76,77]$, and that leukemic CTCL cells produce mainly Th2 cytokines [78]. Taking into consideration that IL-31 is produced mostly by Th2 cells [23] and depends on IL-4 [79], the apparently discrepant results between studies can be explained by differences in patients' characteristics. In fact, $97 \%$ of the patients studied by Singer et al. had advanced disease [49], in comparison to only $15 \%$ of the patients in Malek' study [51] and 31\% in our study. In addition, the proportion of SS patients was much higher in Singer' study (70\%), compared to our study $(33 \%)$ and to Malek's study (3\%). Möbs et al. did not observe significant differences in sIL-31 between itching and nonitching CTCL patients, despite $88 \%$ of the cases having advanced disease and $54 \%$ being SS, neither in between MF and SS patients, nor in between CTCL stages [52]. However, as stated by the authors, "only few samples exceeded the threshold allowing unequivocal sIL-31 quantification," suggesting technical problems [52].

It is still unclear what drives IL-31 production in CTCL and the relative contribution of neoplastic and normal Th2 cells. Evidence supporting the synthesis of IL-31 by neoplastic CTCL cells was provided by three studies. Singer et al. tested CTCL patients and healthy controls for intracellular IL-31, and they found that, upon stimulation with phytohemagglutinin and ionomycin, $\mathrm{CD} 4+\mathrm{T}$ cells (predominantly the neoplastic) from some CTCL patients, all of whom were pruritic, expressed intracellular IL-31 [49]. Möbs et al. observed that IL-31 mRNA was not detectable in blood tumor cells of SS patients, although SC, as normal $\mathrm{T}$ cells, were able to secrete IL-31 upon stimulation [52]. Finally, Cedeno-Laurent et al. found that chemokine receptor type-4-bearing T cells are a main source of IL-31 in CTCL [50]. Thus, it seems that, once activated, both normal and neoplastic T cells can produce IL-31. It could be hypothesized that the stimuli involved in T-cell activation may be infections and bacterial toxins.

Cutaneous colonization with staphylococci is common in CTCL patients and influences disease activity $[55,56]$, and eradication of staphylococci from the skin is associated with clinical improvement [56]. Moreover, staphylococcal superantigens were shown to induce IL-31 expression in the skin from atopic individuals, and in vitro, staphylococcal enterotoxin B induces IL-31 production by leukocytes [30].

Unlike previously observed for AD [60], in our study, sIL-8 was not significantly higher in CTCL patients than in controls, and there was no significant relation between sIL-8 and itch. Interleukin-8 is chemotactic for neutrophils [59], so, as we found, a positive correlation between sIL-8 and neutrophil (and WBC) counts would be expected. 
Neutrophils are a primary line of defense against bacteria. Neutrophil serine proteases, which are released upon neutrophil activation, are major constituents of neutrophil granules [80] and key mediators of inflammation [81-83], participating in microbial destruction and influencing the immune response [80]. For instance, neutrophil-derived proteases have been shown to stimulate proinflammatory cytokines and to activate receptors implicated in itch [84-87]. Some effects of proteases in the skin have been attributed to the activation of the G-protein-coupled PAR, and the role of PAR-2 in skin inflammation and itch is well established [88-93]. Various endogenous [89-92] and exogenous [94-96] proteases, including Staphylococcus toxins [96], have been involved in itch. Therefore, it can be hypothesized that IL-8 may play a part in exacerbating itch in patients with CTCL by recruiting neutrophils into the tissues and promoting the release of neutrophil proteases.

\section{Conclusions}

Our study demonstrates a relationship between sIL-31 and CTCL severity and associated itch, which is frequently recalcitrant and refractory to treatment in such patients. Thus, it would make sense to develop new therapies having IL-31 and its receptor as targets, analogous to what is being carried out for AD [97]. A possible role for IL-8 in exacerbating itch in CTCL patients with concomitant infections needs to be further explored, with emphasis on the bacterial and neutrophil proteases that might be able to induce itch by acting on PAR.

\section{Abbreviations}

$\begin{array}{ll}\text { AD: } & \text { Atopic dermatitis } \\ \text { B2MG: } & \text { Beta } 2 \text { microglobulin } \\ \text { CTCL: } & \text { Cutaneous T-cell lymphoma } \\ \text { EGFR: } & \text { Epidermal growth factor receptor } \\ \text { ELISA: } & \text { Enzyme-linked immunosorbent assay } \\ \text { EORTC: } & \text { European Organization for Research and } \\ & \text { Treatment of Cancer } \\ \text { Hg: } & \text { Hemoglobin } \\ \text { IL: } & \text { Interleukin } \\ \text { ISCL: } & \text { International Society for Cutaneous } \\ & \text { Lymphomas } \\ \text { LDH: } & \text { Lactate dehydrogenase } \\ \text { MF: } & \text { Mycosis Fungoides } \\ \text { PAR: } & \text { Proteinase-activated receptor } \\ \text { PB: } & \text { Peripheral blood } \\ \text { sIL-31: } & \text { IL-31 serum levels } \\ \text { sIL-8: } & \text { IL-8 serum levels } \\ \text { SC: } & \text { Sézary cells } \\ \text { SPSS: } & \text { Statistical package for social sciences } \\ \text { SS: } & \text { Sézary syndrome } \\ \text { TNMB: } & \text { Tumor-node-metastasis-blood } \\ \text { Th1: } & \text { T helper 1 } \\ \text { Th2: } & \text { T helper } 2 \\ \text { VAS: } & \text { Visual analogue scale } \\ \text { WBC: } & \text { White blood cells. } \\ & \end{array}$

\section{Data Availability}

The datasets used and/or analyzed during the current study are available from the corresponding author on reasonable request.

\section{Ethical Approval}

This study was approved by the Ethics Committee and authorized by the Administration Board of Centro Hospitalar Universitário do Porto, Porto, Portugal, study number CHP-2015/137 (124-DEFI/113-CES), and has been carried out in accordance with the Declaration of Helsinki, The Code of Ethics of the World Medical Association for studies involving humans, and European Medicines Agency Guidelines for Good Clinical Practice.

\section{Consent}

Participants were informed of the study's objectives, agreed to take part, and signed informed consent to participate.

\section{Disclosure}

Alice Santos-Silva and Margarida Lima share senior authorship. The authors confirm that the design of the study and collection, analysis, and interpretation of data have not been influenced by the sponsors and neither did the content of the article.

\section{Conflicts of Interest}

The authors declare that they have no conflicts of interest. The authors declare that they have no conflicts of interest. Maria Abreu is currently a resident medical doctor at Centro de Genética Médica Jacinto Magalhães, Centro Hospitalar Universitário do Porto, Porto, Portugal. Marta Miranda is currently a student of Master in Medicine, Faculty of Medicine, University of Porto, Porto, Portugal. Mafalda Castro is currently a hematologist at the Serviço de Hematologia, Unidade Local de Saúde de Matosinhos (ULSM), Porto, Portugal.

\section{Authors' Contributions}

All authors meet the International Committee of Medical Journal Editors (ICMJE) criteria for authorship, take responsibility for the integrity of the work as a whole, and have given their approval to be published. All authors have been involved in study conception and design, analysis and interpretation of data, and drafting the article or revising it critically for important intellectual content, and all authors have read, discussed, and approved the final version of the manuscript. Major contributions were as follows: MA was responsible for data collection and registry and contributed to biochemical studies, statistical analysis, and manuscript writing. MM contributed to biochemical analysis and data interpretation. MC, RC, ICF, and ML were involved in patient care and study implementation. AHS and SF performed lymphocyte immunophenotyping. JR was involved in performed 
genetic studies; CL and ML performed flow cytometry data analysis. IF conducted cytomorphological studies. SC performed biochemical analysis, data interpretation, and discussion. ASS interpreted data, supervised the study, and reviewed the manuscript. ML was involved in study conception and design, study implementation and supervision, patient care, flow cytometry data analysis, clinical and laboratory data review, statistical analysis, data interpretation and discussion, and manuscript writing and review. Maria Abreu contributed to this work as a medical student undertaking training in clinical research. Marta Miranda contributed to this work as part of a graduate program in clinical analysis. Mafalda Castro contributed to this work as part of the residency program in Clinical Hematology. Renata Cabral, MD, a hematologist, and Iolanda Conde Fernandes, $\mathrm{MD}$, a dermatologist, have expertise in clinical support to CTCL. Magdalena Leander, Ana Helena Santos, and Sónia Fonseca are laboratory technicians with expertise in flow cytometry. João Rodrigues is a laboratory technician with expertise in genetics. Catarina Lau, MD, an immunohemotherapist, has expertise in flow cytometry. Inês Freitas, MD, a clinical pathologist, has skills in cytomorphology. Susana Coimbra and Alice Santos Silva, PhD, university professors and researchers, have been dedicated to the identification of disease biomarkers in human diseases. Margarida Lima, MD, $\mathrm{PhD}$, immunohemotherapist, a university professor and researcher, is the head of the Multidisciplinary Out Clinic for Cutaneous Lymphomas and the Unit for Diagnosis in Hematology (Laboratory of Cytometry and Laboratory of Genetics) and has been dedicated to the diagnosis of T-cell lymphoma and to the clinical management of patients with CTCL.

\section{Acknowledgments}

The authors thank medical doctors, nurses, and technicians of the Hematology and Dermatology Departments for support to study implementation. The authors also thank patients and blood donors for their participation. This study was cofinanced by Unidade Multidisciplinar de Investigação Biomédica, Instituto de Ciências Biomédicas Abel Salazar, Universidade do Porto (UMIB/ICBAS/UP), Cooperativa de Ensino Superior Politécnico e Universitário (CESPU), Instituto de Investigação e Formação Avançada em Ciências e Tecnologias da Saúde (IINFACTS) (PI3AC_2016), and Unidade de Ciências Biomoleculares Aplicadas (UCIBIO), Rede de Química e Tecnologia (REQUIMTE), which is financed by national funds from FCT/MEC (UID/Multi/04378/2013) and cofinanced by the ERDF under the PT2020 Partnership Agreement (POCI/ 01/0145/FEDER/007728) and the Norte Portugal Regional Coordination and Development Commission (CCDR-N)/ Norte 2020 (Norte-01-0145-FEDER-000024).

\section{References}

[1] P. T. Bradford, S. S. Devesa, W. F. Anderson, and J. R. Toro, "Cutaneous lymphoma incidence patterns in the United States: a population-based study of 3884 cases," Blood, vol. 113, no. 21, pp. 5064-5073, 2009.
[2] M.-F. Demierre, S. Gan, J. Jones, and D. R. Miller, "Significant impact of cutaneous T-cell lymphoma on patients' quality of life," Cancer, vol. 107, no. 10, pp. 2504-2511, 2006.

[3] R. A. Wilcox, "Cutaneous T-cell lymphoma: 2016 update on diagnosis, risk-stratification, and management," American Journal of Hematology, vol. 91, no. 1, pp. 151-165, 2016.

[4] A. Vij and M. Duvic, "Prevalence and severity of pruritus in cutaneous T cell lymphoma," International Journal of Dermatology, vol. 51, no. 8, pp. 930-934, 2012.

[5] A. Wright, A. Wijeratne, T. Hung et al., "Prevalence and severity of pruritus and quality of life in patients with cutaneous T-cell lymphoma," Journal of Pain and Symptom Management, vol. 45, no. 1, pp. 114-119, 2013.

[6] K. Ahern, E. S. Gilmore, and B. Poligone, "Pruritus in cutaneous T-cell lymphoma: a review," Journal of the American Academy of Dermatology, vol. 67, no. 4, pp. 760-768, 2012.

[7] N. Meyer, C. Paul, and L. Misery, "Pruritus in cutaneous T-cell lymphomas: frequent, often severe and difficult to treat," Acta Dermato Venereologica, vol. 90, no. 1, pp. 12-17, 2010.

[8] R. Twycross, M. W. Greaves, H. Handwerker et al., "Itch: scratching more than the surface," QJM: An International Journal of Medicine, vol. 96, no. 1, pp. 7-26, 2003.

[9] R. L. Thurmond, K. Kazerouni, S. R. Chaplan, and A. J. Greenspan, "Peripheral neuronal mechanism of itch: histamine and itch," in Itch: Mechanisms and Treatment, E. Carstens and T. Akiyama, Eds., CRC Press/Taylor \& Francis, Boca Raton, FL, USA, 2014.

[10] R. L. Thurmond, K. Kazerouni, S. R. Chaplan, and A. J. Greenspan, “Antihistamines and itch,” Pharmacology of Itch, vol. 226, pp. 257-290, 2015.

[11] Ö. Hägermark, T. Hökfelt, and B. Pernow, "Flare and itch induced by substance P in human skin," Journal of Investigative Dermatology, vol. 71, no. 4, pp. 233-235, 1978.

[12] T. Yamaguchi, T. Nagasawa, M. Satoh, and Y. Kuraishi, "Itchassociated response induced by intradermal serotonin through 5-HT2 receptors in mice," Neuroscience Research, vol. 35, no. 2, pp. 77-83, 1999.

[13] Y.-G. Sun and Z.-F. Chen, "A gastrin-releasing peptide receptor mediates the itch sensation in the spinal cord," Nature, vol. 448, no. 7154, pp. 700-703, 2007.

[14] M. G. Swain, "Gastrin-releasing peptide and pruritus: more than just scratching the surface," Journal of Hepatology, vol. 48, no. 4, pp. 681-683, 2008.

[15] G. Heyer, M. Vogelgsang, and O. P. Hornstein, "Acetylcholine is an inducer of itching in patients with atopic eczema," The Journal of Dermatology, vol. 24, no. 10, pp. 621-625, 1997.

[16] T. Akiyama and E. Carstens, "Neural processing of itch," Neuroscience, vol. 250, pp. 697-714, 2013.

[17] U. Neisius, R. Olssonb, R. Rukwied, G. Lischetzki, and M. Schmelz, "Prostaglandin E2 induces vasodilation and pruritus, but no protein extravasation in atopic dermatitis and controls," Journal of the American Academy of Dermatology, vol. 47, no. 1, pp. 28-32, 2002.

[18] T. Andoh and Y. Kuraishi, "Involvement of blockade of leukotriene B4 action in anti-pruritic effects of emedastine in mice," European Journal of Pharmacology, vol. 406, no. 1, pp. 149-152, 2000.

[19] A. E. Kremer, J. J. W. W. Martens, W. Kulik et al., "Lysophosphatidic acid is a potential mediator of cholestatic pruritus," Gastroenterology, vol. 139, no. 3, pp. 1008-1018, 2010. 
[20] T. Andoh and Y. Kuraishi, "Lipid mediators and itch," in Itch: Mechanisms and Treatment, E. Carstens and T. Akiyama, Eds., CRC Press/Taylor \& Francis, Boca Raton, FL, USA, 2012.

[21] T. Akiyama, E. A. Lerner, and E. Carstens, "Protease-activated receptors and itch," Pharmacology of Itch, vol. 226, pp. 219235, 2015.

[22] E. R. Storan, S. M. O'Gorman, I. D. McDonald, and M. Steinhoff, "Role of cytokines and chemokines in itch," Pharmacology of Itch, vol. 226, pp. 163-176, 2015.

[23] M. L. Castellani, P. Felaco, R. J. Galzio et al., "IL-31 a Th2 cytokine involved in immunity and inflammation," International Journal of Immunopathology and Pharmacology, vol. 23, no. 3, pp. 709-713, 2010.

[24] Q. Zhang, P. Putheti, Q. Zhou, Q. Liu, and W. Gao, "Structures and biological functions of IL-31 and IL-31 receptors," Cytokine \& Growth Factor Reviews, vol. 19, no. 5-6, pp. 347-356, 2008.

[25] C. Cornelissen, J. Lüscher-Firzlaff, J. M. Baron, and B. Lüscher, "Signaling by IL-31 and functional consequences," European Journal of Cell Biology, vol. 91, no. 6-7, pp. 552-566, 2012.

[26] T. Hawro, R. Saluja, K. Weller, S. Altrichter, M. Metz, and M. Maurer, "Interleukin-31 does not induce immediate itch in atopic dermatitis patients and healthy controls after skin challenge," Allergy, vol. 69, no. 1, pp. 113-117, 2014.

[27] T. Bando, Y. Morikawa, T. Komori, and E. Senba, "Complete overlap of interleukin-31 receptor $\mathrm{A}$ and oncostatin $\mathrm{M}$ receptor beta in the adult dorsal root ganglia with distinct developmental expression patterns," Neuroscience, vol. 142, pp. 1263-1271, 2016.

[28] I. Arai, M. Tsuji, H. Takeda, N. Akiyama, and S. Saito, "A single dose of interleukin-31 (IL-31) causes continuous itchassociated scratching behaviour in mice," Experimental Dermatology, vol. 22, no. 10, pp. 669-671, 2013.

[29] I. Arai, M. Tsuji, K. Miyagawa, H. Takeda, N. Akiyama, and S. Saito, "Repeated administration of IL-31 upregulates IL-31 receptor A (IL-31RA) in dorsal root ganglia and causes severe itch-associated scratching behaviour in mice," Experimental Dermatology, vol. 24, no. 1, pp. 75-78, 2015.

[30] E. Sonkoly, A. Muller, A. I. Lauerma et al., "IL-31: a new link between T cells and pruritus in atopic skin inflammation," Journal of Allergy and Clinical Immunology, vol. 117, no. 2, pp. 411-417, 2006.

[31] M. Ezzat, Z. Hasan, and K. Shaheen, "Serum measurement of interleukin-31 (IL-31) in paediatric atopic dermatitis: elevated levels correlate with severity scoring," Journal of the European Academy of Dermatology and Venereology, vol. 25, no. 3, pp. 334-339, 2011.

[32] S. Kim, H.-J. Kim, H. S. Yang, E. Kim, I.-S. Huh, and J.-M. Yang, "IL-31 serum protein and tissue mRNA levels in patients with atopic dermatitis," Annals of Dermatology, vol. 23, no. 4, pp. 468-473, 2011.

[33] S. Nobbe, P. Dziunycz, B Mühleisen et al., "IL-31 expression by inflammatory cells is preferentially elevated in atopic dermatitis," Acta Dermato-Venereologica, vol. 92, pp. 24-28, 2012.

[34] U. Raap, S. Weißmantel, M. Gehring, A. M. Eisenberg, A. Kapp, and R. Fölster-Holst, "IL-31 significantly correlates with disease activity and Th2 cytokine levels in children with atopic dermatitis," Pediatric Allergy and Immunology, vol. 23, no. 3, pp. 285-288, 2012.

[35] K. Szegedi, A. E. Kremer, S. Kezic et al., "Increased frequencies of IL-31-producing $\mathrm{T}$ cells are found in chronic atopic dermatitis skin," Experimental Dermatology, vol. 21, no. 6, pp. 431-436, 2012.

[36] K. Siniewicz-Luzeńczyk, A. Stańczyk-Przyłuska, and K. Zeman, "Correlation between serum interleukin-31 level and the severity of disease in children with atopic dermatitis," Postpy Dermatol Alergol, vol. 30, pp. 282-285, 2013.

[37] M. Sokołowska-Wojdyło, J. Gleń, M. Zabłotna et al., "Association of distinct IL-31 polymorphisms with pruritus and severity of atopic dermatitis," The Journal of the European Academy of Dermatology and Venereology, vol. 27, pp. 662664, 2013.

[38] A. Kato, E. Fujii, T. Watanabe et al., "Distribution of IL-31 and its receptor expressing cells in skin of atopic dermatitis," Journal of Dermatological Science, vol. 74, no. 3, pp. 229-235, 2014.

[39] M. Sokołowska-Wojdyło, J. Gleń, M. Zabłotna et al., “The frequencies of haplotypes defined by three polymorphisms of the IL-31 gene: $-1066,-2057$, and IVS2+12 in Polish patients with atopic dermatitis," International Journal of Dermatology, vol. 54, pp. 62-67, 2015.

[40] F. Guarneri, P. L. Minciullo, C Mannucci et al., "IL-31 and IL33 circulating levels in allergic contact dermatitis," European Annals of Allergy and Clinical Immunology, vol. 47, pp. 156-158, 2015.

[41] M. M. Neis, B. Peters, A. Dreuw et al., "Enhanced expression levels of IL-31 correlate with IL-4 and IL-13 in atopic and allergic contact dermatitis," The Journal of Allergy and Clinical Immunology, vol. 118, pp. 930-937, 2015.

[42] M. Czarnecka-Operacz, A. Polańska, M. Klimańska et al., "Itching sensation in psoriatic patients and its relation to body mass index and IL-17 and IL-31 concentrations," Advances in Dermatology and Allergology, vol. 6, pp. 426-430, 2015.

[43] U. Raap, D. Wieczorek, M. Gehring et al., "Increased levels of serum IL-31 in chronic spontaneous urticaria," Experimental Dermatology, vol. 19, no. 5, pp. 464-466, 2010.

[44] K. Welz-Kubiak, A. Kobuszewska, and A. Reich, "IL-31 is overexpressed in lichen planus but its level does not correlate with pruritus severity," Journal of Immunology Research, vol. 2015, Article ID 854747, 11 pages, 2015.

[45] M.-J. Ko, Y.-S. Peng, H.-Y. Chen et al., "Interleukin-31 is associated with uremic pruritus in patients receiving hemodialysis," Journal of the American Academy of Dermatology, vol. 71, no. 6, pp. 1151-1159, 2014.

[46] S. Gangemi, T. Franchina, P. L. Minciullo et al., "IL-33/IL-31 axis: a new pathological mechanisms for EGFR tyrosine kinase inhibitors-associated skin toxicity," Journal of Cellular Biochemistry, vol. 114, no. 12, pp. 2673-2676, 2013.

[47] H. Ohmatsu, M. Sugaya, H. Suga et al., "Serum IL-31 levels are increased in patients with cutaneous T-cell lymphoma," Acta Dermato Venereologica, vol. 92, no. 3, pp. 282-283, 2012.

[48] T. Miyagaki, M. Sugaya, H. Suga et al., "Increased CCL18 expression in patients with cutaneous T-cell lymphoma: association with disease severity and prognosis," Journal of the European Academy of Dermatology and Venereology, vol. 27, no. 1, pp. e60-e67, 2013.

[49] E. M. Singer, D. B. Shin, L. A. Nattkemper et al., "IL-31 is produced by the malignant T-cell population in cutaneous T-Cell lymphoma and correlates with CTCL pruritus," Journal of Investigative Dermatology, vol. 133, no. 12, pp. 2783-2785, 2013.

[50] F. Cedeno-Laurent, E. M. Singer, M. Wysocka et al., "Improved pruritus correlates with lower levels of IL-31 in CTCL patients under different therapeutic modalities," Clin Immunol, vol. 158, pp. 1-7, 2025. 
[51] M. Malek, J. Gleń, K. Rębała et al., "Il-31 does not correlate to pruritus related to early stage cutaneous T-cell lymphomas but is involved in pathogenesis of the disease," Acta Dermato Venereologica, vol. 95, no. 3, pp. 283-288, 2015.

[52] M. Möbs, S. Gryzik, A. Haidar, D. Humme, M. Beyer, and S. Vandersee, "Analysis of the IL-31 pathway in Mycosis fungoides and Sézary syndrome," Archives of Dermatological Research, vol. 307, no. 6, pp. 479-485, 2015.

[53] L. Nattkemper, M. Martinez-Escala, A. Gelman et al., "Cutaneous T-cell lymphoma and pruritus: the expression of IL31 and its receptors in the skin," Acta Dermato Venereologica, vol. 96, no. 7, pp. 894-898, 2016.

[54] P. I. Axelrod, B. Lorber, and E. C. Vonderheid, "Infections complicating mycosis fungoides and sézary syndrome," JAMA: The Journal of the American Medical Association, vol. 267, no. 10, pp. 1354-1358, 1992.

[55] Y. Tokura, H. Yagi, A. Ohshima et al., "Cutaneous colonization with staphylococci influences the disease activity of Sézary syndrome: a potential role for bacterial superantigens," British Journal of Dermatology, vol. 133, pp. 6-12, 1995.

[56] R. Talpur, R. Bassett, and M. Duvic, "Prevalence and treatment of Staphylococcus aureus colonization in patients with mycosis fungoides and Sézary syndrome," British Journal of Dermatology, vol. 159, no. 1, pp. 105-112, 2008.

[57] T. P. Eucker, D. R. Samuelson, M. Hunzicker-Dunn, and M. E. Konkel, "The focal complex of epithelial cells provides a signalling platform for interleukin-8 induction in response to bacterial pathogens," Cellular Microbiology, vol. 16, no. 9, pp. 1441-1455, 2014.

[58] M. Baggiolini and I. Clark-Lewis, "Interleukin-8, a chemotactic and inflammatory cytokine," FEBS Letters, vol. 307, no. 1, pp. 97-101, 1992.

[59] A. Harada, N. Sekido, T. Akahoshi, T. Wada, N. Mukaida, and K. Matsushima, "Essential involvement of interleukin-8 (IL-8) in acute inflammation," Journal of Leukocyte Biology, vol. 56, no. 5, pp. 559-564, 1994.

[60] H. Kimata and I. Lindley, "Detection of plasma interleukin-8 in atopic dermatitis," Archives of Disease in Childhood, vol. 70, no. 2, pp. 119-122, 1994.

[61] M. F. Abdel-Hamid, D. G. Aly, N. E. Saad, H. M. Emam, and D. F. Ayoub, "Serum levels of interleukin-8, tumor necrosis factor- $\alpha$ and $\gamma$-interferon in Egyptian psoriatic patients and correlation with disease severity," The Journal of Dermatology, vol. 38, no. 5, pp. 442-446, 2011.

[62] P. Cardoso, E. Lima, M. M. Lima et al., "Clinical and cytokine profile evaluation in Northeast Brazilian psoriasis plaque-type patients," European Cytokine Network, vol. 27, no. 1, pp. 1-5, 2016.

[63] Y. Hatano, K. Katagiri, and S. Takayasu, "Increased levels in vivo of mRNAs for IL-8 and macrophage inflammatory protein- $1 \alpha$ (MIP-1 $\alpha)$, but not of RANTES mRNA in peripheral blood mononuclear cells of patients with atopic dermatitis (AD)," Clinical \& Experimental Immunology, vol. 117, no. 2, pp. 237-243, 1999.

[64] E. J. Leonard, T. Yoshimura, S. Tanaka, and M. Raffeld, "Neutrophil recruitment by intradermally injected neutrophil attractant/activation protein-1," Journal of Investigative Dermatology, vol. 96, no. 5, pp. 690-694, 1991.

[65] O. Swensson, C. Schubert, E. Christophers, and J.-M. Schröder, "Inflammatory properties of neutrophil-activating protein-1/interleukin 8 (NAP-1/IL-8) in human skin: a light- and electronmicroscopic study," Journal of Investigative Dermatology, vol. 96, no. 5, pp. 682-689, 1991.
[66] B. E. Vaa, A. P. Wolanskyj, L. Roeker et al., "Pruritus in primary myelofibrosis: clinical and laboratory correlates," American Journal of Hematology, vol. 87, no. 2, pp. 136-138, 2012.

[67] R. Willemze, E. S. Jaffe, G. Burg et al., "WHO-EORTC classification for cutaneous lymphomas," Blood, vol. 105, pp. 3768-3785, 2015.

[68] R. Willemze, L. Cerroni, W. Kempf et al., "The 2018 update of the WHO-EORTC classification for primary cutaneous lymphomas," Blood, vol. 133, no. 16, pp. 1703-1714, 2019.

[69] J. J. Scarisbrick, E. Hodak, M. Bagot et al., "Blood classification and blood response criteria in mycosis fungoides and Sézary syndrome using flow cytometry: recommendations from the EORTC cutaneous lymphoma task force," European Journal of Cancer, vol. 93, pp. 47-56, 2018.

[70] E. Olsen, E. Vonderheid, N. Pimpinelli et al., "Revisions to the staging and classification of mycosis fungoides and Sézary syndrome: a proposal of the international society for cutaneous lymphomas (ISCL) and the cutaneous lymphoma task force of the european organization of research and treatment of cancer (EORTC)," Blood, vol. 110, no. 6, pp. 1713-1722, 2007.

[71] M. G. Bernengo, P. Quaglino, A. Comessatti et al., "Low-dose intermittent alemtuzumab in the treatment of Sezary syndrome: clinical and immunologic findings in 14 patients," Haematologica, vol. 92, no. 6, pp. 784-794, 2007.

[72] M. Lima, J. Almeida, M. dos Anjos Teixeira et al., "Utility of flow cytometry immunophenotyping and DNA ploidy studies for diagnosis and characterization of blood involvement in CD4+ Sézary's syndrome," Haematologica, vol. 88, pp. 874887, 2003.

[73] J. Moura, J. Rodrigues, M. Gonçalves, C. Amaral, M. Lima, and E. Carvalho, "Impaired T-cell differentiation in diabetic foot ulceration," Cellular \& Molecular Immunology, vol. 14, no. 9, pp. 758-769, 2017.

[74] J. J. M. van Dongen, A. W. Langerak, M. Brüggemann et al., "Design and standardization of PCR primers and protocols for detection of clonal immunoglobulin and T-cell receptor gene recombinations in suspect lymphoproliferations: report of the BIOMED-2 Concerted Action BMH4-CT98-3936," Leukemia, vol. 17, no. 12, pp. 2257-2317, 2003.

[75] E. Diamandidou, M. Colome, L. Fayad, M. Duvic, and R. Kurzrock, "Prognostic factor analysis in mycosis fungoides/ Sézary syndrome," Journal of the American Academy of Dermatology, vol. 40, no. 6, pp. 914-924, 1999.

[76] G. Saed, D. P. Fivenson, Y. Naidu, and B. J. Nickoloff, "Mycosis fungoides exhibits a Th1-type cell-mediated cytokine profile whereas sezary syndrome express a Th2-type profile," Journal of Investigative Dermatology, vol. 103, no. 1, pp. 29-33, 1994.

[77] E. Papadavid, J. Economidou, A. Psarra et al., "The relevance of peripheral blood T-helper 1 and 2 cytokine pattern in the evaluation of patients with mycosis fungoides and sezary syndrome," British Journal of Dermatology, vol. 148, no. 4, pp. 709-718, 2003.

[78] E. Guenova, R. Watanabe, J. E. Teague et al., "TH2 cytokines from malignant cells suppress TH1 responses and enforce a global TH2 bias in leukemic cutaneous T-cell lymphoma," Clinical Cancer Research, vol. 19, no. 14, pp. 3755-3763, 2013.

[79] B. Stott, P. Lavender, S. Lehmann, D. Pennino, S. Durham, and C. B. Schmidt-Weber, "Human IL-31 is induced by IL-4 and promotes TH2-driven inflammation," Journal of Allergy and Clinical Immunology, vol. 132, no. 2, pp. 446-454, 2013. 
[80] B. Korkmaz, T. Moreau, and F. Gauthier, "Neutrophil elastase, proteinase 3 and cathepsin G: physicochemical properties, activity and physiopathological functions," Biochimie, vol. 90, no. 2, pp. 227-242, 2008.

[81] C. T. N. Pham, "Neutrophil serine proteases: specific regulators of inflammation," Nature Reviews Immunology, vol. 6, no. 7, pp. 541-550, 2006.

[82] U. Meyer-Hoffert and O. Wiedow, "Neutrophil serine proteases: mediators of innate immune responses," Current Opinion in Hematology, vol. 18, no. 1, pp. 19-24, 2011.

[83] D. A. Stapels, B. V. Geisbrecht, and S. H. Rooijakkers, "Neutrophil serine proteases in antibacterial defense," Current Opinion in Microbiology, vol. 23, pp. 42-48, 2015.

[84] U. Meyer-Hoffert, J. Wingertszahn, and O. Wiedow, "Human leukocyte elastase induces keratinocyte proliferation by epidermal growth factor receptor activation," Journal of Investigative Dermatology, vol. 123, no. 2, pp. 338-345, 2004.

[85] K. Mihara, R. Ramachandran, B. Renaux, M. Saifeddine, and M. D. Hollenberg, "Neutrophil elastase and proteinase-3 trigger $\mathrm{G}$ protein-biased signaling through proteinase-activated receptor-1 (PAR1)," Journal of Biological Chemistry, vol. 288, no. 46, pp. 32979-32990, 2013.

[86] C. J. Kuckleburg and P. J. Newman, "Neutrophil proteinase 3 acts on protease-activated receptor-2 to enhance vascular endothelial cell barrier function," Arteriosclerosis, Thrombosis, and Vascular Biology, vol. 33, no. 2, pp. 275-284, 2013.

[87] R. Ramachandran, K. Mihara, H. Chung et al., "Neutrophil elastase acts as a biased agonist for proteinase-activated receptor-2 (PAR2)," Journal of Biological Chemistry, vol. 286, no. 28, pp. 24638-24648, 2011.

[88] C. Kempkes, J. Buddenkotte, F. Cevikbas, T. Buhl, and M. Steinhoff, "Role of PAR-2 in neuroimmune communication and itch," in Itch: Mechanisms and Treatment, E. Carstens and T. Akiyama, Eds., CRC Press/Taylor \& Francis, Boca Raton, FL, USA, 2014.

[89] R. Costa, D. M. Marotta, M. N. Manjavachi et al., "Evidence for the role of neurogenic inflammation components in trypsin-elicited scratching behaviour in mice," British Journal of Pharmacology, vol. 154, no. 5, pp. 1094-1103, 2008.

[90] K. Stefansson, M. Brattsand, D. Roosterman et al., "Activation of proteinase-activated receptor-2 by human kallikrein-related peptidases," Journal of Investigative Dermatology, vol. 128, no. 1, pp. 18-25, 2008.

[91] M. Steinhoff, U. Neisius, A. Ikoma et al., "Proteinase-activated receptor-2 mediates itch: a novel pathway for pruritus in human skin," The Journal of Neuroscience, vol. 23, pp. 6176-6180, 2004.

[92] O. Hagermark, G. Rajka, and U. Bergvist, "Experimental itch in human skin elicited by rat mast cell chymase," Acta Dermato-Venereologica, vol. 52, pp. 125-128, 1972.

[93] T. Kawakami, K. Kaminishi, Y. Soma, T. Kushimoto, and M. Mizoguchi, "Oral antihistamine therapy influences plasma tryptase levels in adult atopic dermatitis," Journal of Dermatological Science, vol. 43, no. 2, pp. 127-134, 2006.

[94] V. B. Reddy, A. O. Iuga, S. G. Shimada, R. H. LaMotte, and E. A. Lerner, "Cowhage-evoked itch is mediated by a novel cysteine protease: a ligand of protease-activated receptors," Journal of Neuroscience, vol. 28, no. 17, pp. 4331-4335, 2008.

[95] T. Kato, T. Takai, T. Fujimura et al., "Mite serine protease activates protease-activated receptor- 2 and induces cytokine release in human keratinocytes," Allergy, vol. 64, no. 9, pp. 1366-1374, 2009.
[96] M. Bukowski, B. Wladyka, and G. Dubin, "Exfoliative toxins of Staphylococcus aureus," Toxins, vol. 2, no. 5, pp. 1148-1165, 2010.

[97] O. Nemoto, M. Furue, H. Nakagawa et al., "The first trial of CIM331, a humanized antihuman interleukin-31 receptor a antibody, in healthy volunteers and patients with atopic dermatitis to evaluate safety, tolerability and pharmacokinetics of a single dose in a randomized, double-blind, placeboco," British Journal of Dermatology, vol. 174, no. 2, pp. 296-304, 2016. 